ГАНТУЛГА Дамдин Ph.D. в области культурологии, заведующий кафедрой дизайна Ховдского государственного университета,

Ховд, Монголия Damdin GANTULGA Ph.D. in Cultural Studies, Head, Department of Design, Khovd State University, Khovd, Mongolia, gantulga9913@gmail.com ORCID: 0000-0002-8468-8548

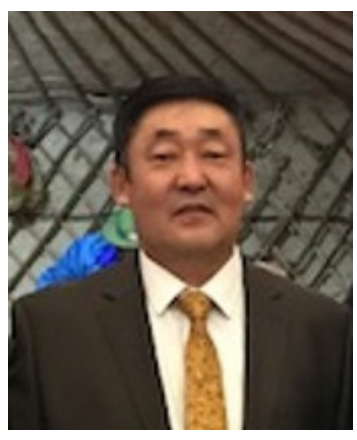

БАТЫРЕВА Светлана Гарриевна доктор искусствоведения,

ведущий научный сотрудник отдела истории, археологии и этнологии Калмыцкого научного центра Российской Академии наук,

Элиста, Российская Федерация Svetlana G. BATYREVA

Dr. Sci. (Fine and Applied Art and Architecture), Leading Researcher, Kalmyk Scientific Center of the Russian Academy of Sciences, Elista, Russian Federation, sargerel@mail.ru ORCID: 0000-0003-4268-0705

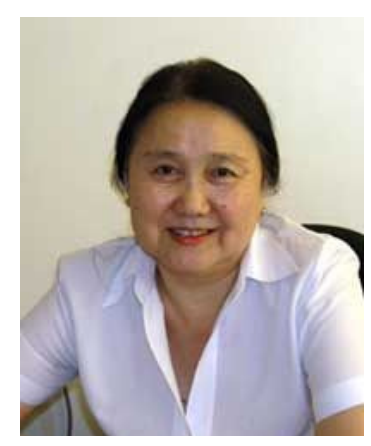

УДК 745/749(517.3)"652":130.121.4

DOI: 10.36343/SB.2020.24.4.005

ГРНТИ 18.31.51

BAK 24.00.01

\author{
Основные принципы \\ смысловыражения \\ в декоративно-прикладном \\ искусстве древней Монголии ${ }^{1}$
}

\author{
Basic Principles \\ of Meaning Expression \\ in the Applied Arts \\ of Ancient Mongolia ${ }^{2}$
}

В статье рассматривается проблема влияния концептов сознания, разделявшихся творцами древней культуры Монголии на образы, заложенные в произведениях декоративноприкладного творчества. В качестве стержневой идеи такого смысловыражения принято учение арга билиг. Материалами послужили произведения древнего искусства Монголии и результаты исследований монгольских и российских археологов, искусствоведов и культурологов. Изучены

\footnotetext{
${ }^{1}$ Статья написана при поддержке гранта РФФИ № 19-512-44002/19 «Народное декоративно-прикладное искусство ойратов Монголии и калмыков России: общее и особенное в сравнительно-сопоставительном анализе».

2 The article was written with the support of the grant of the Russian Foundation for Basic Research, Project No. 19-512- 44002/19 “Folk Arts and Crafts of the Oirats of Mongolia and the Kalmyks of Russia: General and Special in Comparative Analysis".
} 
традиционные принципы и символика монгольского декоративно-прикладного искусства. На многочисленных примерах (оленные камни, гуннское литье, печати ханов, стеганый войлок и т. д.) показаны основные образы, свойственные искусству древней Монголии, определены принципы создания символического изображения. Сделан вывод, что благодаря сочетанию принципов «арга» и «билиг» монгольское искусство во все времена являет собой органическое единство взаимосвязанных частей, сплетенное из элементов, по смыслу своему принадлежащих одному из двух противоположных полюсов мироздания.

Ключевые слова: смысловыражение, арга билиг, Монголия, декоративно-прикладное искусство, оленные камни, звериный стиль, гуннское литье, орнамент.

Введение. Перед исследователями каждого поколения стоит задача поиска сущности взаимозависимых связей, возникающих при создании художественного образа как результата отражения реальности. При этом анализ и обобщение явлений культуры, созданной человечеством, предполагает необходимость выявления средств и способов образного выражения произведений искусства. Последние не являются прямым отражением реальной жизни. Суть явлений искусства и их происхождение следует искать во внутренней скрытой сущности каждого реального предмета или явления, проецируемой в сферу мышления древнего человека, которое одухотворяет видимые и невидимые факты реальности через призму мифологического мировидения [1, с. 47-64].

Монгольский народ многое внес в сокровищницу мировой и евразийской культуры, о чем имеются многочисленные свидетельства, отраженные в научных исследованиях, посвященных культуре оленных камней [8] [5], образам животных в древнем искусстве [7], культуре печатей и знаков, гуннскому искусству [11] и т. д. Большой интерес представляет изучение символического значения древних памятников и изображений на них, ставших объектом пристального внимания монгольских и российских ученых сравнительно недавно [1] [3] [4] [7]. Данная проблема прежде всего подразумевает научное изучение особенностей мифологического сознания с целью выявления его основных (осевых) концептов. Применительно к древней культуре Монголии и ее создателям роль такой осевой концепции играет учение арга билиг, предполага- ющее существование Вселенной в условиях постоянной борьбы, равновесия и единства двух упомянутых противоположных начал.

Цель настоящего исследования заключается в том, чтобы выявить основные проявления влияния учения арга билиг на смысловыражение в древнем монгольском искусстве, охарактеризовав принципы изображения символических мотивов.

Древнее искусство Монголии зародилось 3200 лет тому назад, основными материалами для его изучения являются произведения народного декоративно-прикладного творчества. В методологическом аспекте исследование этих произведений с точки зрения выявления их смыслового содержания обеспечивается использованием принципов и приемов, присущих семиотике пространства, в частности, учению о «символических формах», разработанному Э. Кассирером [6]. Эта концепция предполагает, во-первых, наличие связей между пространством и смыслом, во-вторых, первичность символической (смысловыражающей) функции пространственных объектов и, в-третьих, постулирование мифологического пространства, пронизанного собственными качествами и смыслами, каждый объект которого (вещь, место, идея, направление движения и т. д.) обладает своим значением, а само это пространство - устойчивой системой связей между элементами [6, с. 99-100]. Именно эти положения методологической схемы Э. Кассирера представляются приемлемыми для научного описания семантики монгольского традиционного искусства как системы, рожденной мифологическим сознанием, в контексте концепции арга билиг. 
Между тем вопросы методологического характера применительно к исследованию древнего искусства Монголии еще требуют глубокого изучения и в настоящее время только начинают разрабатываться, при этом постоянно уточняются методы исследования художественных образов.

Изучение и установление принципов смысловыражения как наследия человечества в истории культуры подготовлено многовековым путем развития гуманитарного знания. Раскрытие их, на наш взгляд, может дать ответы на многие актуальные вопросы, связанные с реконструкцией основополагающей идеи национальной культуры монголов, скрытой «под пылью времен», и выявить роль различных внешних влияний, вносивших свою лепту в данный процесс. Научно обоснованное понимание культуры необходимо в современных условиях господства общества потребления со свойственными ему постоянными изменениями, вызванными развитием компьютерных технологий и модернизацией производительных сил человечества. Трудно переоценить его значение для формирования аксиологических установок молодого поколения, а также в процессе создания культурного иммунитета и защиты наследия от волн глобализации. В свою очередь, сохранение культурного наследия также является особо актуальной проблемой, ожидающей оптимального решения в обществе, заинтересованном в будущем своей культуры. Как уже было подчеркнуто, в настоящей работе основное внимание уделяется такой яркой составляющей наследия монгольских народов, как народное декоративно-прикладное искусство.

При создании любого произведения монгольского народного декоративного искусства мастера прежде всего опираются на взаимозависимость «единодушных» свойств арга и билиг - коренных основ мировоззрения кочевников. Они несут в своей структуре принципы смысловыражения художественного образа, и их постижение основывается на обязательном соотнесении с образами, представляющими «три материка» духовности, сотворяющими макропространство кочевой культуры.
Огромное количество взаимосвязей между идеями, существующими в пространстве макромира культуры, обусловливает характер мышления кочевников, более обширного и даже необъятного, кардинально отличающегося от других форм пространственного мышления. Необходимо заметить, что создание образа человеком является двусторонним, реально и абстрактно взаимозависимым процессом. Даже самый небольшой уклон в сторону одной из двух противоположных сторон творчества приводит к потере художественного качества творческого труда $[10$, с. 325$]$. В рамках мировидения, воплощенного в народном искусстве, образ имеет форму, взятую из реальной действительности. Таковы, в частности, пространственные формы существующей природы. В результате взаимосвязей этих явлений и форм, отражающих реальный мир и мировоззрение данного народа, согласно принципам смысловыражения создается художественный образ [2].

Метод смысловыражения в данном исследовании рассматривается лишь применительно к сфере народного искусства. Это художественное мышление творца, основывающееся на принципах, унаследованных многими поколениями. Установленные веками принципы творчества, пронизанные глубокой народностью, традициями культуры, обусловливают своеобразие форм культуры человечества, различных по своему происхождению и внешним качествам.

Историко-культурные памятники: традиционные принципы и символика в монгольском декоративно-прикладном искусстве. Монголия - это страна, сохранившая мечты и деяния человека в памятниках культуры, самые ранние из которых относятся к эпохе палеолита и значение которых не расшифровано до настоящего времени. Исследователи отмечают, что «в географическом положении страна является местом возникновения и пересечения центральных и важных направлений, определявших процесс формирования древних племен и этносов, их передвижение с доисторических времен и распространение культурных достижений, одной из немногих стран, богатых галереями петроглифов» [9, с. 103]. Невозможно в рамках одной 
статьи рассмотреть «долгосрочный исторический путь культурной идеи», эволюцию ее формирования и развитие принципов ее создания, поэтому в исследовании приходится ограничиваться периодом так называемых оленных камней ${ }^{1}$, созданных в эпоху позднего бронзового и раннего железного века. В работе мы обращаемся к трудам, посвященным зооморфному искусству гуннской государственности, развивающему принципы традиционного смысловыражения в монгольском искусстве.

Оленные камни определяют время зарождения идеи «о трех материках», сохраняемой монголами по сей день. Характер изображений на них доказывает, что к моменту появления этих памятников принципы смысловыражения в монгольском искусстве были уже достаточно глубоко разработаны. Именно начиная с эпохи оленных камней макромир древнего искусства разделяется на три материка: верхний, средний и нижний. Среди них главенствуют верхний и нижний миры, рассматриваемые в свете упомянутых взаимосвязей арга и билиг. Их взаимозависимость определяет существование пространства среднего мира - мира людей, придающего гармонию двум другим мирам, которые создают «единодушную» внутреннюю структуру макромира. Данная идея была воплощена в каменных галереях под открытым небом и оставлена нам в наследство, являясь главной осью развития кочевого бытия, пронизывающей все формы монгольской культуры.

Исследовательский коллектив во главе с археологом Ц. Турбатом, итоги работы которого были отражены в труде «Монголия и региональная культура оленных камней», изучил 1241 памятник, тем самым осмыслив достижения кочевой культуры, созданной якобы на западной окраине степей Евразии. Между тем в настоящее время существует точка зрения о том, что культура оленных камней была создана в Монголии, потом распространившись на территорию

\footnotetext{
1 Оленные камни - древние памятники монументального искусства, представляющие собой стелы с выбитыми или нанесенными охрой стилизованными изображениями животных (чаще всего оленей), распространенные в Монголии, Тыве, Забайкалье, Китае (прим. ред.).
}

Восточной Европы. Данная точка зрения вновь получила свое подтверждение в свете последних археологических открытий: «Культура оленных камней, возникшая 3200 лет тому назад, бытовала более шести столетий, оставив глубокий след в генезисе кочевников, в их истории и культуре. Не ограничиваясь этим, возможно делать смелые выводы о том, что народы, создавшие первую государственность, сотворили и оленные камни. Культура оленных камней и керексуров ${ }^{2}$, распространявшаяся от Хэнтэйского нагорья до Кыргызстана и гор Тяньшаня, занимавшая 1,8 млрд квадратных километров, была первой по времени возникновения великой культурой кочевников Центральной Азии. Звериный стиль искусства кочевников, созданный творцами оленных камней, считается самостоятельным жанром, занявшим прочное место в сокровищнице культуры и искусства человечества. На материале оленных камней можно восстановить систему представлений о мире кочевников конца бронзового века» [8, с. 9-10].

Колесообразный круг, берущий свое начало от эпохи оленных камней, представляет собой небо, землю и человека, то есть верхний, средний и нижний материки-миры. Представление о мире вошло в общественное сознание и утвердилось, трансформировавшись в изображение круга и чандмань (орнамент, состоящий из трех каплевидных знаков: один сверху и два внизу). В колесообразном круге - вечное синее небо ханов. В таком виде изображение колеса дошло до нашего времени, не изменяя своего смысла за весь последующий период существования монгольской культуры. Кратко характеризуя его, следует упомянуть оленные камни и литье, относящееся к творениям звериного стиля искусства гуннов. Сюда необходимо отнести гуннский стеганый войлок, найденный при раскопках горы Ноён-Ула, тамги и пе-

\footnotetext{
2 Керексуры (от монг. Хиргисүүр - киргизская могила) - древние погребальные сооружения, курганные насыпи из грунта и камней, окруженные каменной оградой; иногда включали расходяшиеся от центра к ограде каменные вымостки-«лучи». Памятники этого типа расположены в Монголии, Тыве, Алтае и Забайкалье (прим. ред.).
} 

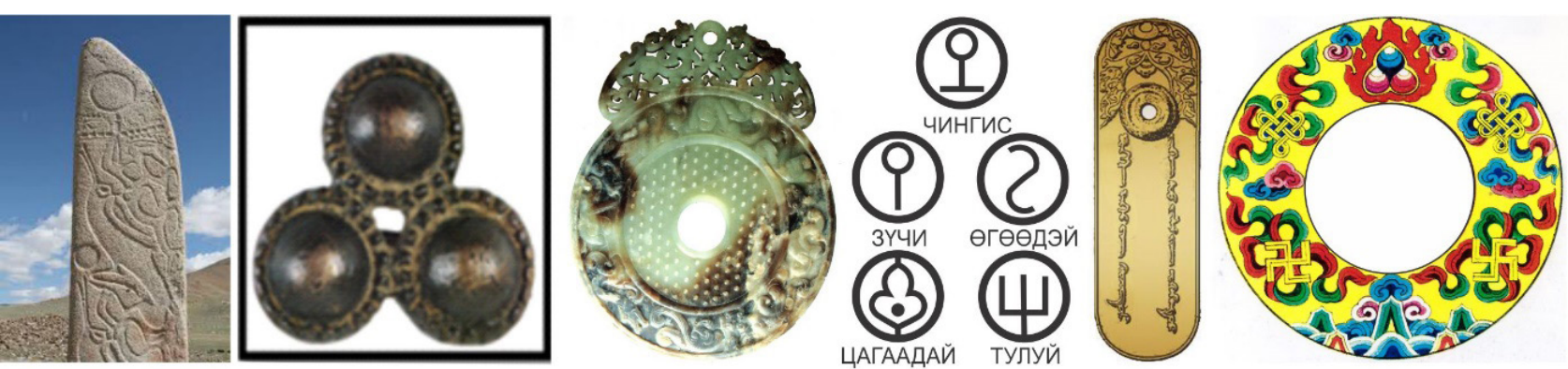

Рисунок 1

чати больших и малых ханов, гэрэгэ (знак посланца Чингисхана), отличительные знаки на правом и левом плечах Богдохана (рисунок 1).

Из них следует выделить колесообразный круг яшмового изделия, найденного в 1-ом кургане местности Гол-Мод-2 и представляющий собой пример звериного стиля, свойственного искусству гуннов. Об этом, в частности, свидетельствует описание предмета: «В верхней части яшмового изделия (ширина 15 см, высота 4,5 см) изображены два диких животных рода ирбис. Снежные барсы держат зубами с двух сторон колесо диаметром в два сантиметра. В центре яшмового изделия рельефно сделан круг диаметром 11,5 см, на этом круге вырезаны девять диких животных. Изображение их будто проколото насквозь по обе стороны» [5, с. 14-19].

Изображения животных - ирбиса, снежного барса, объемлющих колесообразный круг с двух сторон, - появляется в верхней части гэрэгэ Чингисхана. Девять диких животных на яшмовом изделии соответствуют традиции выражения верхнего «материка» этим числом; животные, расположенные среди облаков в сказочно-мифологической призме изображения, и другие сюжеты точно совпадают с тра- дициями образного смысловыражения, символически представляющими ханов. Изображения колесообразного круга позже станут отличительными плечевыми знаками Богдохана.

В гуннскую эпоху искусство звериного стиля получило новый виток творческого развития. Это доказано историческими фактами, подтверждаемыми данными археологических исследований [5, с. 14-19]. Памятники гуннов, найденные в г. Ноён-Ула, Тахилтын-Хотгор, Гол-Мод, р. Эгийн-Гол, долине р. Туул, Морин-Толгой, Бага Газрын Чулуу, Балгасын-Тал и др., были созданы в символике художественных образов, свидетельствующих о высоком развитии искусства изготовления золотых и серебряных изделий. В частности, несомненный интерес представляют находки, обнаруженные в ходе работ по проекту Гол-Мод-2 в степи Балгасын-Тал (сомон Ундур-Улаан Архангайского аймака) под руководством доктора Д. Эрдэнэбаатара. Среди них особенно выделяются фигуры единорогов (самца и самки) на подгруднике и подхвостнике снаряжении для лошадей, запрягаемых в карету, на которой ездили гуннские аристократы. На золотых и серебряных круглых и овальных деталях изображены ферзь, белый снежный барс и рельефные украше-
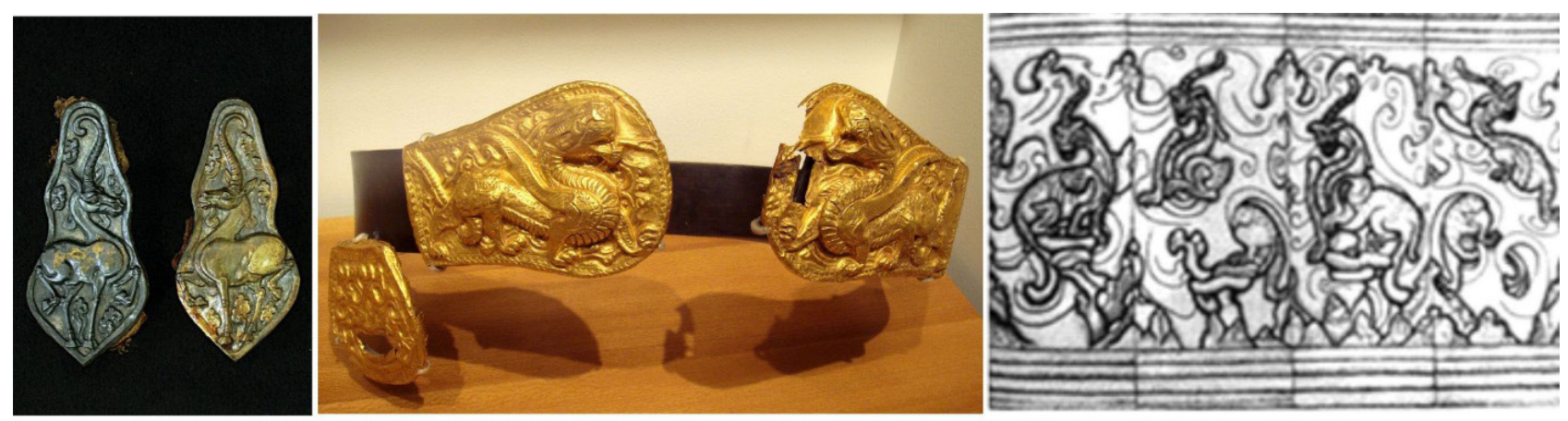

Рисунок 2 
ния - детали пояса с изображением Золотого Дракона, принадлежности гуннского властителя Шаньюя (рисунок 2).

По ним можно получить полное представление о находке - «бронзовой подпорке, украшенной рельефными изображениями и линией облачного орнамента, беспрерывно продолжающегося с одной стороны на другую на расстоянии 12,3-12,5 см. На каждой стороне изображено символическое животное с одним рогом, головой тигра, шеей дракона с четырьмя ногами, с маленькими крылышками в верхней части передних ног - среди облаков в четырех различных композициях [3, с. 138]. По этому предмету, изготовленному методом чеканки тонкой металлической пластины, можно определить отправную точку искусства звериного стиля, каковой можно считать разработку однорогого образа, представителя верхнего мира, созданного в качестве ханского символа. Идею и принципы его развития в изображении облачного верхнего мира представляет мотив, определяемый как арга и проявившийся уже в этот период.

Одним из наиболее сильных мифических однорогих животных является дракон. Доктор Д. Эрдэнэбаатар, научный руководитель проектов Гол-Мод-1 и Гол-Мод-2, особо подчеркивал, что «из однорогих животных дракон - это ханский символ» $[11$, с. 138]. Одинокое дерево, растущее в степях, на перевалах и холмах, называют «единственное верхнее дерево <...> развеси- стое дерево», что также связано с древним мифологическим мышлением. В образном смысловыражении отражен древний культ, бытовавший в течение того долгого времени, когда монголы обладали властью, определяя развитие исторического процесса на огромных пространствах. Таковы памятники культуры, созданные в традициях образного смысловыражения, к которым мы вернемся при исследовании принципов создания образа.

Принципы создания символического изображения. В монгольском народном декоративно-прикладном искусстве образы выражаются в формах, как правило, выполненных в технике резьбы. Орнамент, печати и знаки, сакральные знамена, песни, хореография, пластичные танцы, обряды и игры - все это содержит и выражает скрытый смысл, базируясь на идее о взаимодействии арга и билиг - принципов смысловыражения, рассматриваемых в качестве причин и следствий тех или иных явлений. Процесс искусного создания произведения является выражением и выявлением следствия в связи с материальной средой и ее производительными силами, выступающими в этом процессе как действующие причины. Деятельность по созданию образа и включению его в пространство микромира народного декоративно-прикладного искусства образует три следующие тесно взаимосвязанные в соответствии с данной схемой части (рисунок 3):

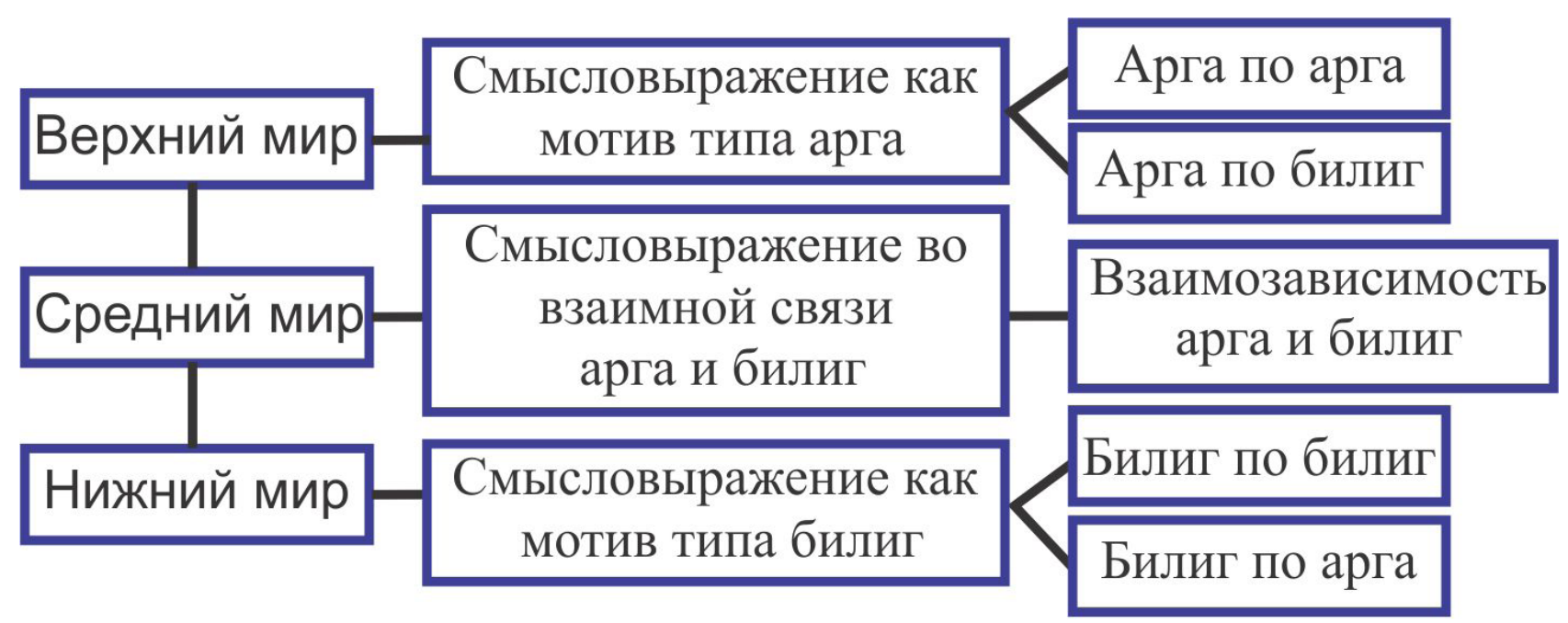

Рисунок 3 

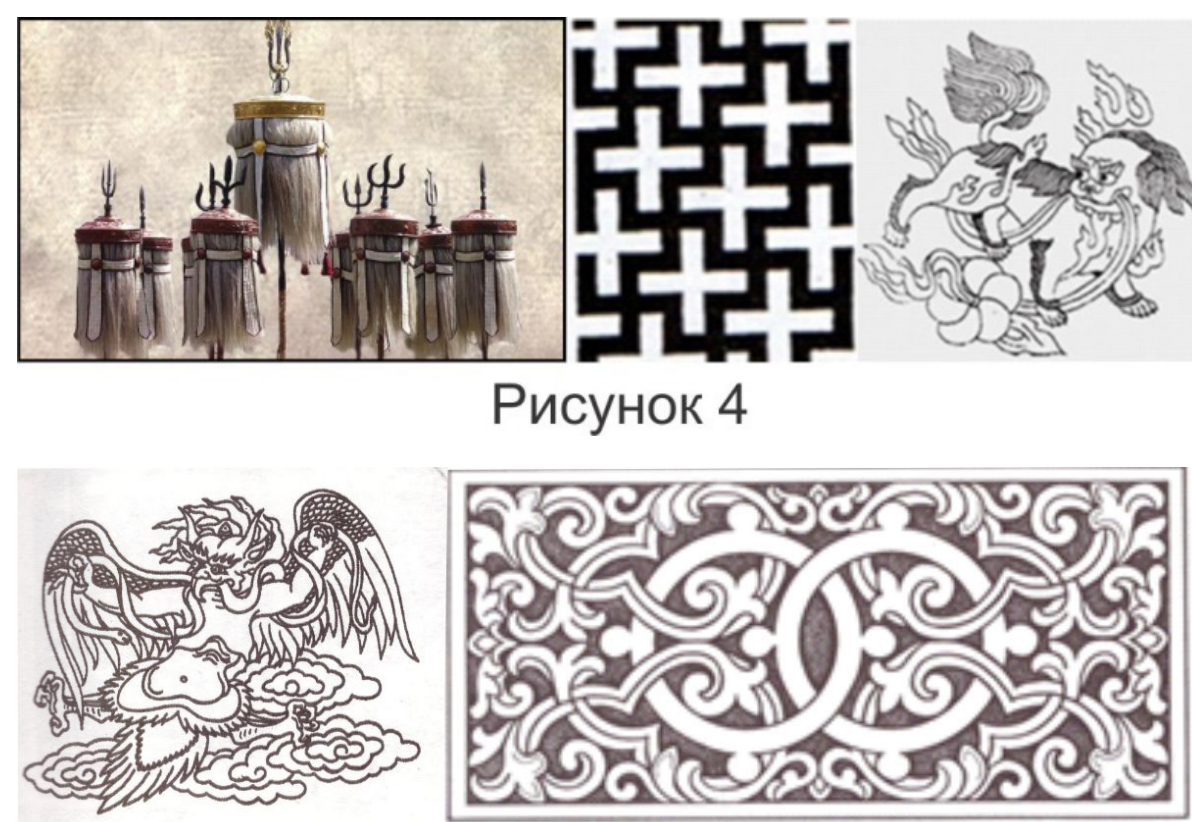

Рисунок 5

Первая часть схемы (по вертикали) представляет собой выражение вселенского пространства (макромира) в трех мирах; вторая - процесс разработки образов по принципам смысловыражения через взаимодействие арга и билиг, третья - введение полученных образов (художественных форм) в систему культуры в качестве символов [3, с. 83].

Символика (или смысл изображения) как фактор создания образа в монгольском народном декоративно-прикладном искусстве определена тремя принципами.

Смысловыражение мотивов типа apгa. Изображения подобных образов соответствуют верхнему неорганическому миру, одному из главных факторов в системе трех материков макромира. В зависимости от того, какая часть макромира (совокупности трех миров) выступает в качестве вспомогательного образа, символика мотивов типа арга подразделяется на две части. Главный смысл содержания образа верхнего мира зафиксирован в мотивах типа арга (рисунок 4). Образы, содержащие главный смысл верхнего мира, получают развитие в образе нижнего мира с пространственным началом во взаимной связи, что образует мотив типа билиг по арга (рисунок 5).

При создании мотивов типа арга в монгольсоком народном декоративно-прикладном искусстве соблюдается следующий общий принцип представления образов, олицетворяющих верхний мир в южном, юго-западном, западном, северо-западном направлениях: «Небо определяет направление движения по солнечному кругу и выше, стремящиеся (к небу) направления, южные склоны, мужской образ с коренными свойствами, далее не распадающийся на формы и объемы, созданные силой (однорогие животные, посвященные верхнему миру), облака, колесообразный круг, четверо сильнейших, пернатые, дикие животные, мужчина). Образы в цветовом отношении: белый и красный, число - 9, ритм неравный, нечетный, выражаемый числами $3,5,7,9,13 »[4$, с. 170].

Принцип изображения символических мотивов типа билиг. Данные образы принадлежат нижнему (органическому) миру, одной из основ макромира. В своем значении они взаимосвязаны с образами, выбранными как из верхнего (неорганического), так и из нижнего (органического) миров. В зависимости от того, как сотворен главный образ, его развитие вспомогатель-

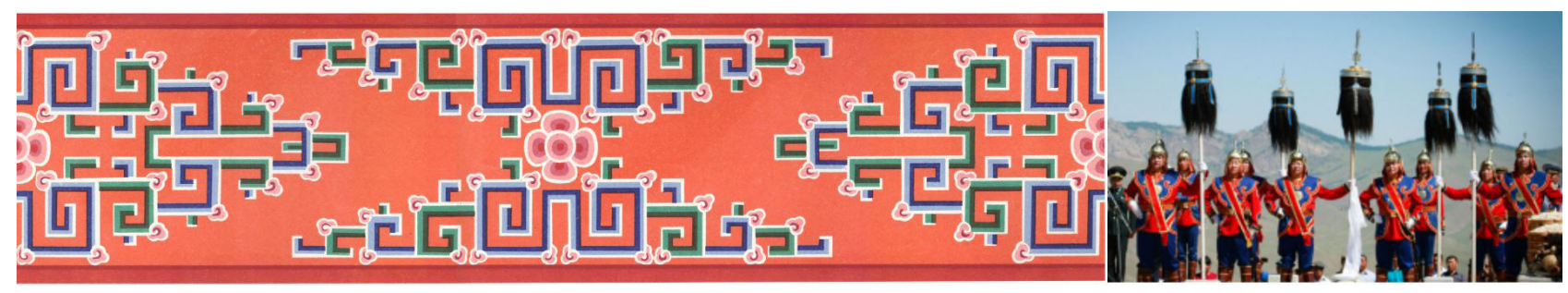

Рисунок 6 

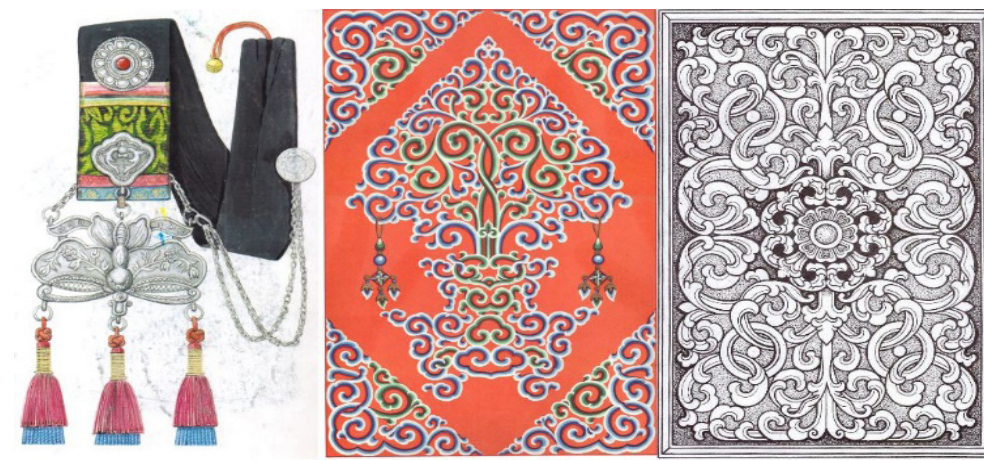

Рисунок 7

ными образами, относящимися к верхнему и нижнему материкам макромира, определено принципом смысловыражения мотивов типа билиг (рисунок 6).

Таким образом, выражение главного смысла из нижнего материка следует развивать образом того же пространства, поставив их во взаимную связь, что будет являться принципом смысловыражения мотивов типа билиг по билиг (рисунок 7).

При создании символического смысловыражения в народном декоративно-прикладном искусстве «придерживаются принципа, согласно которому общие формы и объемы данного предмета или вещей дальше распадаются, разделяются на образы спокойствия (пять видов скота, травоядные животные, цветы и листья, травы, кустистые и древесные растения, цветы, бабочки, змея, водные орнаменты). Для них характерны повторы сюжетов в ритме и движении с четными числами $(2,4,6,8,10,12)$, вращения против часовой стрелки, цветовая символика: черный, зеленый, желтый; направления: север, северо-восток, восток, юго-восток. Общая форма изображения: в земных пропорциях, положение горизон- тальное, представляющее нижний мир» [7, с. 188].

Принцип изображения символики образов во взаимосвязях арга и билиг. Взаимные связи верхнего и нижнего материков определяют символическую значимость изображения. Пространство среднего материка закономерно взаимозависимо с представляющими его образами [11, с. 89]. Главными произведениями, выполненными по принципу изображения взаимной связи арга и билиг, являются предметы бронзового литья с мотивами звериного стиля, $a$ также орнаментальные изображения. Среди этих культурных форм - произведения, созданные в эпоху звериного стиля и являющиеся образами, представляющими верхний и нижний материки: это произведение с изображением борьбы дикого зверя с травоядным домашним животным, что можно считать выражением взаимозависимых закономерностей существования верхнего и нижнего материков макромира. Мотивы единоборства животных с эпохи господства звериного стиля становятся одним из главных принципов декорации макропространства нашей кочевой культуры (рисунок 8).

Изображение реальных животных в дальнейшем обогащается более искусными и абстрактными формами. Это, в частности, отображение животного с украшением его задней части маленькими полусферами; изображение звериных тел со временем становится более изощренным, с переходом в орнаментальный сюжет, иногда с потерей в узорных деталях оригинального образа - таким представляется процесс развития
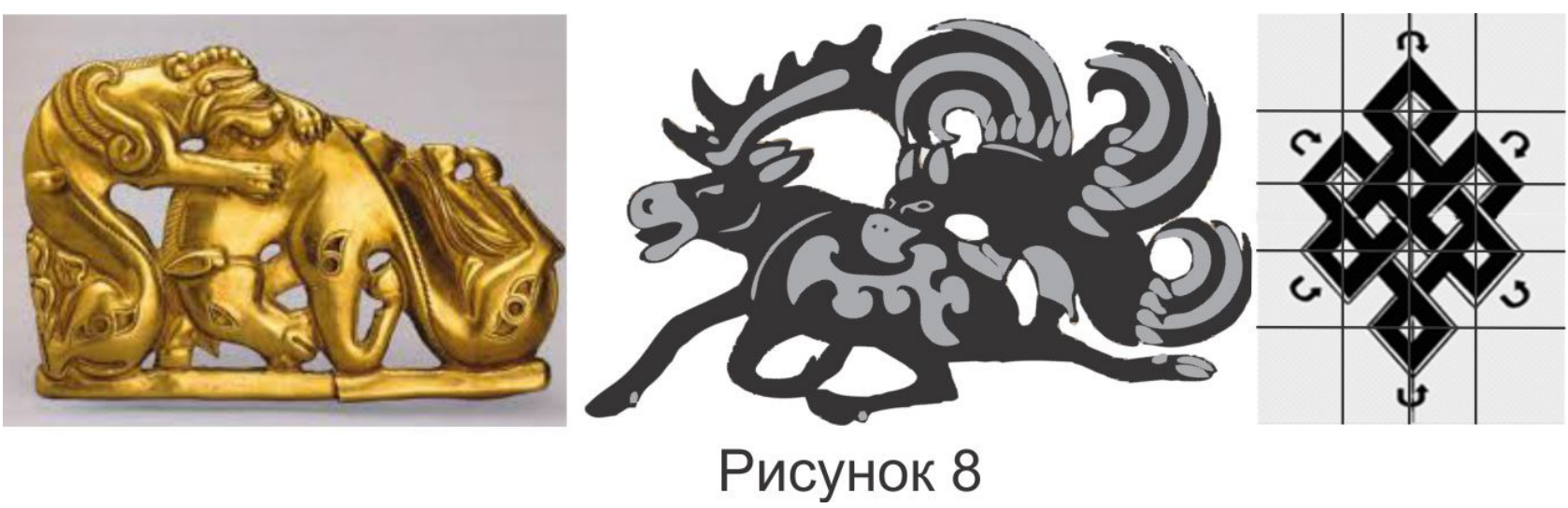

\section{Рисунок 8}


искусства, унаследованный от предков. Несмотря на дальнейшую эволюцию производительных сил и повышение творческих способностей при создании любых продуктов труда (в том числе и произведений искусства), подобная традиция не прерывается и сегодня, находя продолжение в монгольском народном декоративно-прикладном искусстве, выражаясь в беспрерывном процессе его современного развития.

Выводы. Гармоничное существование в целостной системе макромира является осевой идеей кочевой культуры. Все формы монгольской художественной культуры, возникшие и развивающие принципы смысловыражения в народном декоратив- но-прикладном искусстве, дошли до наших дней в тесном взаимодействии между собой. В монгольском народном искусстве эта закономерность выводится из двух факторов, обусловливающих попарные изображения во взаимной зависимости, - мотивов типа арга и мотивов типа билиг, а также взаимосвязанных арга и билиг. Эти факторы возникли в ходе исторической эволюции кочевой культуры в пространстве декоративно-прикладного искусства и стали принципами ее смысловыражения. Их формирование на протяжении многих тысяч лет обрело форму художественных традиций народного декоративно-прикладного искусства.

\section{Damdin GANTULGA}

Ph.D. in Cultural Studies, Head, Department of Design,

Khovd State University,

Khovd, Mongolia,

gantulga9913@gmail.com

ORCID: 0000-0002-8468-8548

Svetlana G. BATYREVA

Dr. Sci. (Fine and Applied Art and Architecture),

Leading Researcher,

Kalmyk Scientific Center of the Russian Academy of Sciences,

Elista, Russian Federation, sargerel@mail.ru

ORCID: 0000-0003-4268-0705

\section{Basic Principles of Meaning Expression} in the Applied Arts of Ancient Mongolia

Abstract. The authors consider the problem of the influence of the concepts of Mongolian ancient culture creators' consciousness on the images inherent in the works of applied arts they created. The doctrine arga bilig, which proceeds from the understanding that harmony in the world is determined by the struggle and unity of two opposing principles, is accepted as the core idea of such meaning expression. The materials for the study were the works of Mongolia's ancient art and the results of research by Mongolian and Russian archaeologists, art historians and cultural scientists. The methodology of the work was formed by the approaches adopted in the semiotics of space and the concept of "symbolic forms" developed by Ernst Cassirer and reflecting the properties of mythological consciousness. The essence of the concepts arga and bilig as the fundamental foundations of the worldview of ancient Mongolia's nomads is revealed. The traditional principles and symbols of Mongolian arts and crafts are studied. The authors examine the symbolism of the deer stone culture, noting that it originated in Mongolia, and then spread to the territory of Eastern Europe. In the aspect of analyzing the symbolic meaning, the works of Hun casting (animal style), khans' seals, quilted felt are studied. The main images inherent in the ancient and medieval art of Mongolia are shown, the principles of creating a symbolic image are determined. The principles that determine the meaning 
expression of the motives of the arga type (its images correspond to the Upper World in the structure of the Mongols' mythological consciousness) are revealed. The principle of depicting symbolic motifs of the bilig type (according to the views of representatives of the nomadic culture, it belongs to the Lower World) is revealed. The mutual connections of the Upper and Lower Worlds, embodied in symbols, determine the semantic fullness and significance of the image. The authors point out that the main works, made according to the principle of depicting the mutual connection of arga and bilig, are bronze casting objects with animal style motives, as well as ornamental compositions. The authors conclude that, due to the combination of the principles of arga and bilig, Mongolian art at all times represents an organic unity of interconnected parts, woven from elements that, in their meaning, belong to one of the two opposite poles of the universe. This unity is the pivotal idea of the nomadic culture and determines its harmonious existence in the integral system of the macrocosm.

Keywords: meaning expression, arga bilig, Mongolia, applied arts, deer stones, animal style, Hun casting, ornament.

\section{Использованная литература:}

1. Батчулуун Л. Монгол гэрийн модны хээ угалз, өнгө тогтолцооны уламжлал, шинэчлэлийн асуудалд [Деревянные орнаменты монгольских гер: традиции и нововведения цветовой системы]. Улаанбаатар: б. и., 1989. Х. 47-64.

2. Батырева С.Г. Войлок в музейном собрании Государственного Эрмитажа: к вопросу образного мышления номадов Центральной Азии // Вестник Калмыцкого университета. 2018. № 3 (39). С. 6-13.

3. Гантулга Д. Монголчууд үлэмж ертөнцийн орон зайд [Монголы в огромном мире]. Улаанбаатар: Голден легион, 2017.

4. Гантулга Д. Монголчуудын дүр, дүрсэнд арга, билгийг шүтэлцүүлэх сэтгэлгээ [Менталитет ассоциирующих приемов и мудрость образа монголов] // «Хэл, соёл, соёл хоорондын харилцаа»: Олон улсын эрдэм шинжилгээний хурал №2. [2-я Международная научная конференция «Язык, культура и межкультурные отношения]. Ховд: Соёмбо принтинг, 2010. Х. 170.

5. Гантулга Д. Художественная выразительность оленных камней // Искусство Евразии. Международный научный журнал. № 2 (5) 2017. С. 14-19.

6. Кассирер Э. Философия символических форм. Т. 2. Мифологическое мышление. М.; СПб.: Университетская книга, 2002.

7. Константы культуры России и Монголии: очерки истории и теории. Барнаул: Алтайский дом печати, 2010. С. $144-148$.

8. Монгол ба бүс нутгийн буган хөшөөний соёл. Эрдэм шинжилгээний каталог. Тэргүүн боть. [Монгольская и региональная культура оленных камней. Каталог исследований. Первый том.] / Ц. Төрбат (Ред.). Улаанбаатар: ШУА-ийн Түүх, археологийн хүрээлэн [Институт истории и археологии Академии наук Монголии], 2018. X. 9-10.

9. Окладников А. П. Центрально-Азиатский очаг первобытного искусства. М.: Наука, 1972.

10. Рубинштейн С. Л. Основы общей психологии. М.: Учпедгиз, 1946.

11. Эрдэнэбаатар Д., Идэрхангай Т. Балгасын тал дахь Гол-Мод-2-ын Хүннүгийн язгууртны булшны судал-

\section{References:}

1. Batchuluun, L. (1989) Mongol geriin modny khee ugalz, öngö togtoltsoony ulamjlal, shinechleliin asuudald [Wooden Ornaments of Mongolian Heroes: Traditions and Innovations of the Color System]. Ulaanbaatar: [s.n.]. pp. 4764. (In Mongolian).

2. Batyreva, S. G. (2018) Voylok v muzeynom sobranii Gosudarstvennogo Ermitazha: $\mathrm{k}$ voprosu obraznogo myshleniya nomadov Tsentral'noy Azii [Samples of Felt in the Collection of the State Hermitage Museum: The Issue of Central Asian Nomads' Figurative Thinking]. Vestnik Kalmytskogo universiteta - Bulletin of Kalmyk University. 39. pp. 6-13. (In Russian)

3. Gantulga, D. (2017) Mongolchuud ülemj yertöntsiin oron zaid [Mongolians in the Vast World]. Ulaanbaatar: Golden legion. (In Mongolian).

4. Gantulga, D. (2010) [The Mentality of Associating Methods and Wisdom of the Image of Mongolians]. Khel, soyol, soyol khoorondyn khariltsaa [Language, Culture and Intercultural Relations]. Proceedings of the 2nd International Conference. Khovd: Soembo printing. (In Mongolian).

5. Gantulga, D. (2017) Artistic expressiveness of deer stones. Iskusstvo Evrazii - The Art of Eurasia. 2 (5) pp. 14-19. (In Russian). DOI: 10.25712/ASTU.2518-7767.2017.02.002

6. Cassirer, E. (2002) Filosofiya simvolicheskikh form [Philosophy of Symbolic Forms]. Translated from German by S.A. Romashko. Vol. 2. Moscow; Saint Petersburg: Universitetskaya kniga.

7. Shishin, M.Yu. \& Makarova, E.V. (eds) (2010) Konstanty kul'tury Rossii i Mongolii: ocherki istorii $i$ teorii [Constants of Culture of Russia and Mongolia: Essays on History and Theory]. Barnaul: Altayskiy dom pechati. pp. 144-148.

8. Törbat, Ts. (ed.) (2018) Mongol ba büs nutgiin bugan khöshöönii soyol. Erdem shinjilgeenii katalog [Mongolian and Regional Culture of Deer Stones. Research Catalog]. Vol. 1. Ulaanbaatar: Institute of History and Archeology of the Mongolian Academy of Sciences. pp. 9-10. (In Mongolian).

9. Okladnikov, A.P. (1972) Tsentral'no-Aziatskiy ochag pervobytnogo iskusstva [The Central Asian Center of Primitive Art]. Moscow: Nauka. 
гаа [Исследование кургана гуннской знати Гол-Мод-2 в Балгасских степях]. Улаанбаатар: Мөнхийн үсэг ХХК, 2015. Х. 138
10. Rubinshteyn, S.L. (1946) Osnovy obshchey psikhologii [Fundamentals of General Psychology]. Moscow: Uchpedgiz.

11. Erdenebaatar, D. \& Iderkhangay, T. (2015) Balgasyn tal dakhi Gol mod-2-yn Khünnügiin yazguurtny bulshny sudalgaa [Survey of the Mound of the Xiongnu Elite at Gol Mod 2 in the Balgas Steppe]. Ulaanbaatar: Mönkhiin üseg KhKhK. (In Mongolian).

\section{Полная библиографическая ссылка на статью:}

Гантулга Д. Основные принципы смысловыражения в декоративно-прикладном искусстве древней Монголии / Д. Гантулга, С. Г. Батырева, // Наследие веков. - 2020. - № 4 - C. 53-63. DOI: 10.36343/SB.2020.24.4.005

Full bibliographic reference to the article:

Gantulga, D. \& Batyreva, S.G. (2020) Basic Principles of Meaning Expression in the Applied Arts of Ancient Mongolia. Nasledie vekov - Heritage of Centuries. 4. pp. 53-63. (In Russian). DOI: 10.36343/SB.2020.24.4.005 